Provided for non-commercial research and education use. Not for reproduction, distribution or commercial use.

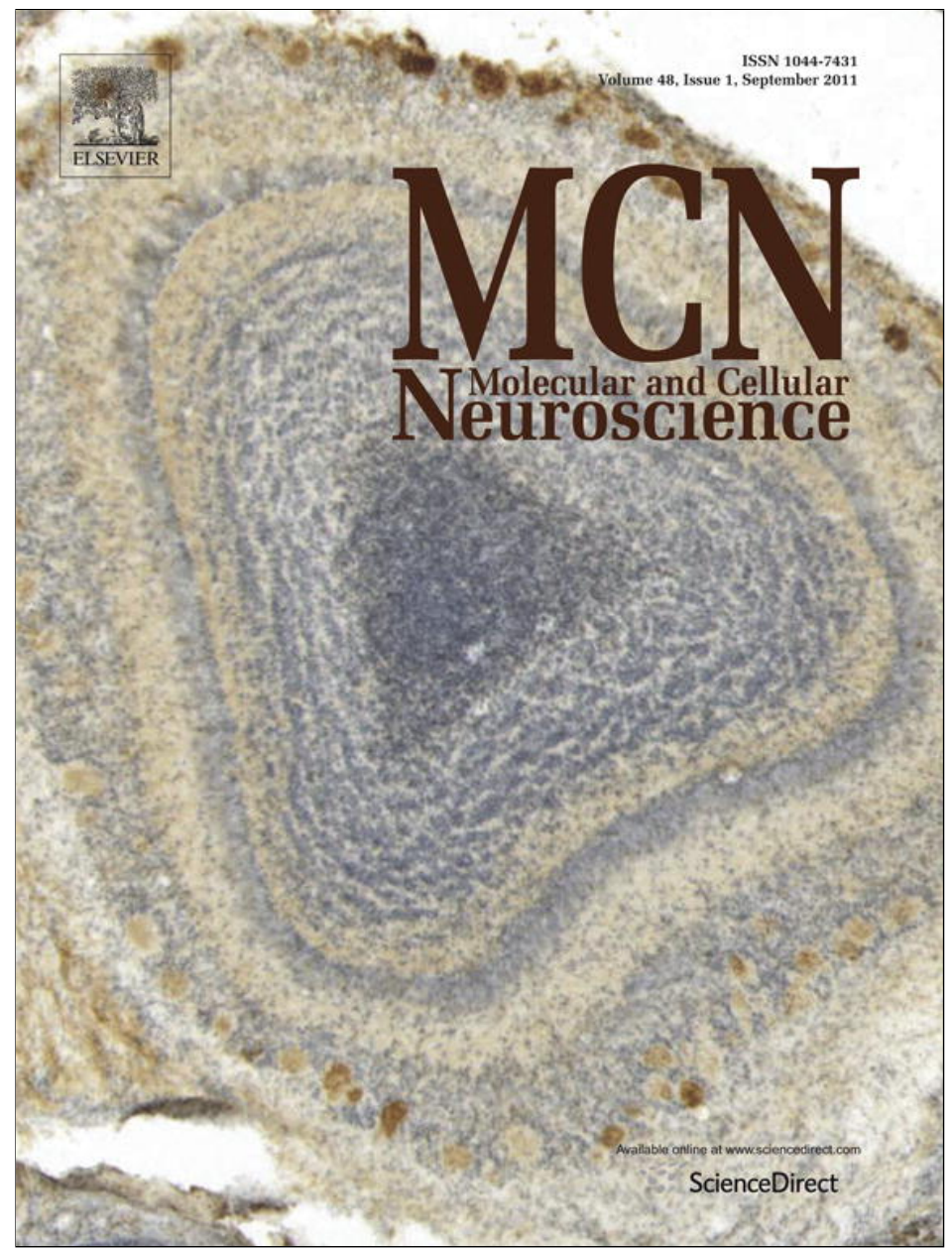

This article appeared in a journal published by Elsevier. The attached copy is furnished to the author for internal non-commercial research and education use, including for instruction at the authors institution and sharing with colleagues.

Other uses, including reproduction and distribution, or selling or licensing copies, or posting to personal, institutional or third party websites are prohibited.

In most cases authors are permitted to post their version of the article (e.g. in Word or Tex form) to their personal website or institutional repository. Authors requiring further information regarding Elsevier's archiving and manuscript policies are encouraged to visit:

http://www.elsevier.com/copyright 


\title{
Evidence for the interaction of D-amino acid oxidase with pLG72 in a glial cell line
}

\author{
Silvia Sacchi ${ }^{\mathrm{a}, \mathrm{b}}$, Pamela Cappelletti ${ }^{\mathrm{a}, \mathrm{b}}$, Stefano Giovannardi ${ }^{\mathrm{a}}$, Loredano Pollegioni ${ }^{\mathrm{a}, \mathrm{b}, *}$ \\ a Dipartimento di Biotecnologie e Scienze Molecolari, Università degli studi dell'Insubria, via J. H. Dunant 3, 21100 Varese, Italy \\ b "The Protein Factory", Centro Interuniversitario di Ricerca in Biotecnologie Proteiche Politecnico di Milano and Università degli studi dell'Insubria, Italy
}

\section{A R T I C L E I N F O}

\section{Article history:}

Received 16 February 2011

Revised 29 April 2011

Accepted 1 June 2011

Available online 12 June 2011

\section{Keywords:}

D-serine

Neurotransmission

Schizophrenia

Flavoprotein

NMDA receptor

Subcellular localization

\begin{abstract}
A B S T R A C T
Accumulating genetic evidence indicates that the primate-specific gene locus G72/G30 is related to schizophrenia: it encodes for the protein pLG72, whose function is still the subject of controversy. We recently demonstrated that pLG72 negatively affects the activity of human D-amino acid oxidase (hDAAO, also related to schizophrenia susceptibility), which in neurons and (predominantly) in glia is expected to catabolize the neuromodulator D-serine. The D-serine regulation mechanism relying on hDAAO-pLG72 interaction does not match with the subcellular localizations proposed for hDAAO (peroxisomes) and pLG72 (mitochondria). By using glioblastoma U87 cells transfected with plasmids encoding for hDAAO and/or pLG72 we provide convergent lines of evidence that newly synthesized hDAAO, transitorily present in cytosol before being delivered to the peroxisomes, colocalizes and interacts with pLG72 which we propose to be exposed on the external membrane of mitochondria. We also report that newly synthesized cytosolic hDAAO is catalytically active, and therefore pLG72 binding-and ensuing hDAAO inactivation-plays a protective role against D-serine depletion.
\end{abstract}

(C) 2011 Elsevier Inc. All rights reserved.

\section{Introduction}

Astrocytes release numerous molecules that can modulate synaptic transmission and synchronize neuronal network activity. One such signaling molecule is D-serine. This "atypical" neuromodulator is produced through the isomerization reaction catalyzed by the enzyme serine racemase (SR) from L-serine (Wolosker et al., 1999) and degraded by the $\alpha, \beta$-elimination reaction of SR and/or by oxidative deamination catalyzed by the FAD-containing flavoprotein D-amino acid oxidase (DAAO) (Baumgart and Rodríguez-Crespo, 2008; Pollegioni et al., 2007; Pollegioni and Sacchi, 2010). D-Serine binds to the "glycine site" of the N-methyl-D-aspartate subtype of glutamate receptors (NMDAr), which, together with the glutamate site, must be occupied for the receptor to operate. D-Serine plays key roles in excitatory synaptic transmission and in several pathological conditions and is important for a number of physiological processes involved in neuronal plasticity (Martineau et al., 2006; Oliet and Mothet, 2009; Schell, 2004).

Different studies indicated that D-serine levels are decreased in schizophrenic patients (Bendikov et al., 2007; Hashimoto et al., 2003) and D-serine greatly ameliorated the symptoms of schizophrenia when administered together with conventional neuroleptics (Heresco-Levy et al., 2005). Schizophrenia is a complex disease: a collection of signs and

* Corresponding author at: Dip. Biotecnologie e Scienze Molecolari, Università degli studi dell'Insubria, Varese, Italy. Fax: +39 332421500.

E-mail address: loredano.pollegioni@uninsubria.it (L. Pollegioni). symptoms of unknown etiology, primarily defined by observed signs of psychosis. At least 43 candidate genes associated with a risk for schizophrenia have been identified, but individual effect sizes are modest (Insel, 2010). Among the possible schizophrenia susceptibility genes, polymorphisms, and haplotypes in the genes encoding for DAAO, pLG72 and SR have been identified, reviewed in (Pollegioni and Sacchi, 2010). The human G72 gene encodes for pLG72, a protein present only in primates, which interacts with human DAAO (hDAAO) in astrocytes (Chumakov et al., 2002; Sacchi et al., 2008). We recently demonstrated that in vitro pLG72 inactivates hDAAO (Molla et al., 2006a,b) and that cellular concentrations of D-serine depend on expression of the active form of this flavooxidase. Therefore, we proposed a model for schizophrenia susceptibility in which a decrease in pLG72 expression yields an anomalously high level of DAAO activity and induces an excessive decrease in the local concentration of D-serine (Sacchi et al., 2008). Here, the subcellular localization of hDAAO and pLG72 represents a major concern: DAAO is a well-known peroxisomal enzyme targeted to this compartment by the C-terminal PTS1 sequence (Arnold et al., 1979; Moreno et al., 1999; Sacchi et al., 2008; Pollegioni and Sacchi, 2010). However, there is controversy concerning the subcellular distribution of pLG72: it has been proposed as a mitochondrial protein (Benzel et al., 2008; Kvajo et al., 2008), but in human cultured astrocytes it showed a perinuclear and tubular distribution (Sacchi et al., 2008). Indeed, only $5 \%$ of the latter cells displayed (cytosolic) overlapping signals for pLG72 and hDAAO, with a mean average of $8 \%$ colocalization. These observations suggested that pLG72 interaction with hDAAO is probably driven by specific spatiotemporal stimuli, whose features were elusive. 
In the present study we investigated the subcellular localization and interaction of hDAAO with pLG72 by using U87 glioblastoma cells transiently or stably transfected with plasmids encoding for fluorescent-tagged pLG72 and/or hDAAO. We solved the apparent discrepancy between the different subcellular localization of the two proteins and their putative interaction, enlightening the effect of this interaction on D-serine metabolism.

\section{Results}

hDAAO and pLG72 (apparently) localize to different cellular compartments

The hDAAO-pLG72 interaction has been previously studied in vitro by using different biochemical approaches (Chumakov et al., 2002; Sacchi et al., 2008). We also demonstrated that fusion of the GFP protein with hDAAO does not alter its biochemical properties (Caldinelli et al., 2010). As native hDAAO, the EGFP-hDAAO is fully active, binds one molecule of FAD per protein monomer (with a $\mathrm{K}_{\mathrm{d}}$ of $7 \mu \mathrm{M}$ ), and interacts with pLG72, yielding a complex constituted by two hDAAO homodimers and two pLG72 molecules; indeed, the time course for inactivation of the EGFP-hDAAO-pLG72 complex closely resembles that observed for native hDAAO. To investigate subcellular localization (and interaction) of hDAAO and pLG72 in depth, U87 glioblastoma cells were transfected with plasmids encoding for the corresponding tagged proteins (see Supplemental Materials). U87 Clones stably expressing EYFP-hDAAO (U87 EYFP-hDAAO cells), hDAAO-EYFP (U87 hDAAO-EYFP cells), or pLG72-ECFP (U87
pLG72-ECFP cells) were then isolated in D-MEM medium to which G418 was added. Confocal microscopy shows that, in the U87 pLG72-ECFP clone, the signal corresponding to the expressed pLG72-ECFP protein displays a peculiar "spaghetti like" distribution around the nucleus (Fig. 1A). In contrast, the EYFP-hDAAO signal is near a punctuate subcellular structure (Fig. 1B) and differs from the (cytosolic) one observed for the U87 hDAAO-EYFP cells (in which the C-terminal peroxisomal targeting signal -SHL of the overexpressed protein is masked by the fused EYFP, Fig. 1C). Since DAAO is known to be a peroxisomal enzyme (Arnold et al., 1979; Moreno et al., 1999; Sacchi et al., 2008; Pollegioni and Sacchi, 2010), we used U87 EYFP-hDAAO cells in the present study, in addition to U87 pLG72-ECFP cells, as a cellular system model. In order to exclude an effect of the specific tag on the cellular distribution of the overexpressed proteins, similar experiments were also carried out using U87 cells stably expressing pLG72-FLAG and untagged hDAAO proteins (panels D and E of Fig. 1). In these cells the signal distribution of both proteins closely resembled that observed for pLG72-ECFP and EYFP-hDAAO, respectively.

Expression of the full-length, fluorescent fusion proteins in the selected, stable clones was confirmed by Western blot analysis. A single band corresponding to EYFP-hDAAO $(66.4 \mathrm{kDa})$ is detected in U87 EYFP-hDAAO (Fig. 1F, lane 3, $\alpha$-DAAO panel). A significant expression of the full-length pLG72-ECFP in the U87 pLG72-ECFP clone (Fig. 1F, lane 5, $\alpha$-GFP panel) is also apparent: in addition to the 46-kDa band of the pLG72-ECFP fusion protein, a 28-kDa band corresponding to the ECFP moiety was also detected.
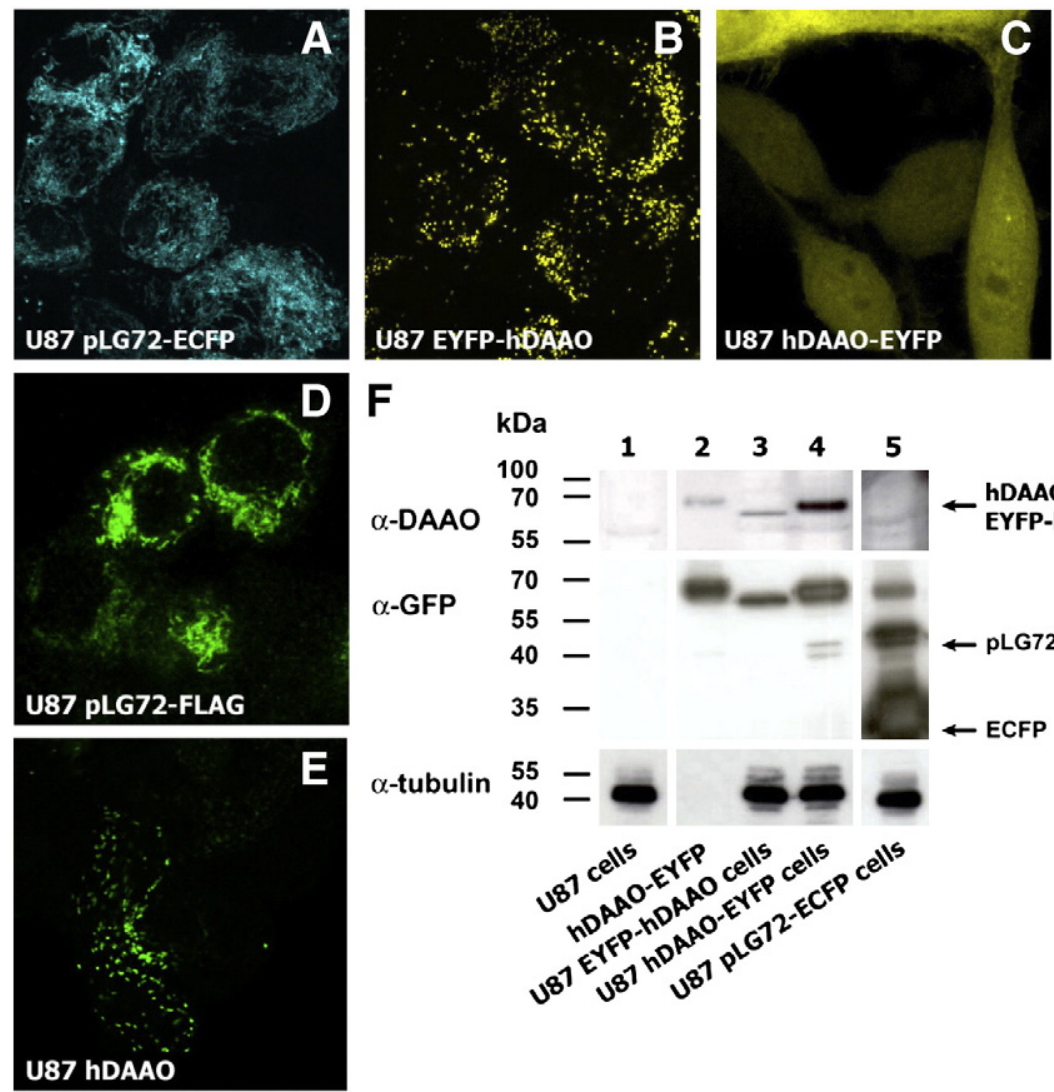

$\alpha$-tubulin

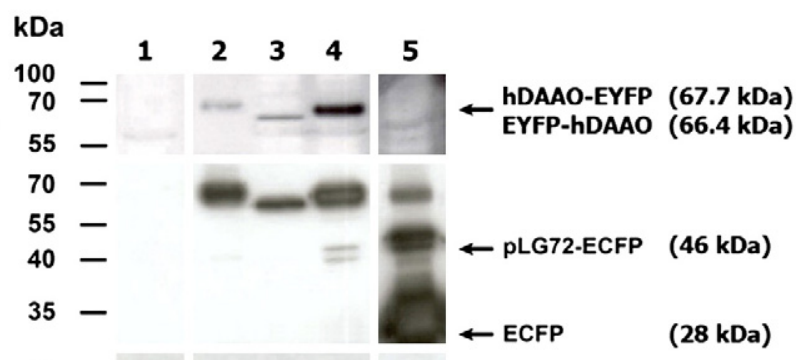

Fig. 1. Expression of chimeric fluorescent hDAAO and pLG72 proteins in stably transfected U87 glioblastoma cells (A-E). Confocal analysis showing distribution of the different fluorescent chimeric proteins (panels A-D) and untagged hDAAO (panel E) in selected U87 clones. pLG72-ECFP and pLG72-FLAG display a "spaghetti like", perinuclear distribution (A and D), while the punctuate localization of EYFP-hDAAO and untagged hDAAO (labeled using sheep anti-hDAAO and donkey anti-sheep Alexa 488 antibodies) indicate internalization into organelles (B and E). The hDAAO-EYFP shows a diffused, cytosolic distribution since the PTS1 signal at the C-terminus of hDAAO is masked by EYFP (C). F) Western blot analysis performed using rabbit anti-hDAAO and mouse anti-GFP antibodies confirms expression of the different fluorescent fusion proteins in transfected U87 cells. The same amount of sample (corresponding to $5 \times 10^{4}$ cells) was loaded in each lane, as further confirmed by using an anti- $\alpha$-tubulin antibody as internal control (bottom panel). hDAAO-EYFP $(0.03 \mu \mathrm{g}$, lane 2$)$ recombinant purified protein was used as positive control. The level of endogenous hDAAO and pLG72 in U87 control cells is below the detection limit $(\leq 0.005 \mu \mathrm{g}$ for hDAAO and $\leq 0.025 \mu \mathrm{g}$ for pLG72), see lane 1 . 
Confocal analysis suggests that EYFP-hDAAO, as well as untagged hDAAO, is mainly targeted to peroxisomes since the distribution of the labeled PMP70 (70-kDa peroxisomal membrane protein) overlaps with the fluorescence signal corresponding to the flavoprotein (Fig. 2A, B). Moreover, pLG72-ECFP and pLG72-FLAG exhibit a perinuclear, "spaghetti like" signal which largely colocalizes with a specific mitochondrial marker (Fig. 2C, F): in contrast, no overlapping signal distribution is observed using PMP70 or $58 \mathrm{~K}$ protein (Fig. 2D, E and $\mathrm{G}$ ) as markers of peroxisomes and Golgi apparatus compartments, respectively. A clear colocalization was also observed for the pLG72ECFP and Mitotracker Green FM dye, used as a marker of mitochondria (not shown). Therefore, this experimental evidence indicates that EYFP-hDAAO and pLG72-ECFP fusion proteins show distinct cellular

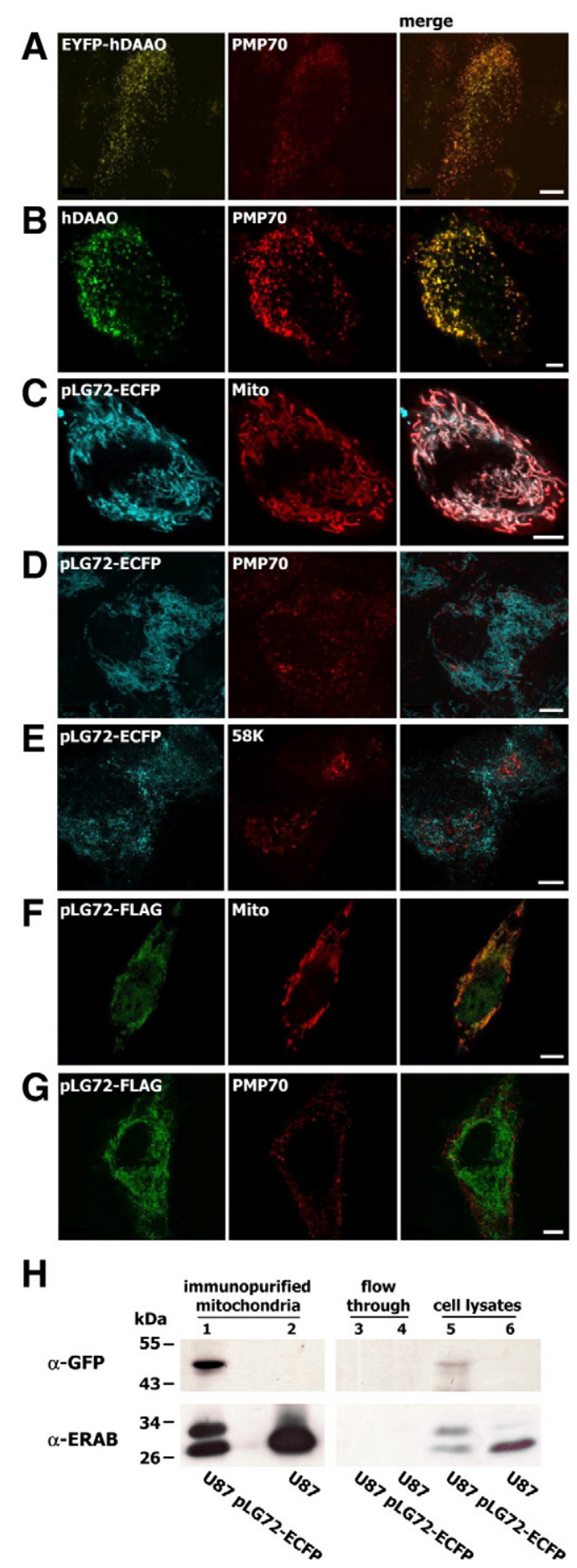

localizations. Notably, we recently demonstrated that, in cultured human secondary astrocytes, endogenous pLG72 showed a different, punctuate signal pattern which colocalized with hDAAO to a minor extent $(<10 \%)$ (Sacchi et al., 2008). Nonetheless, the experimental evidence obtained here using the U87 human glioblastoma cell systems expressing EYFP-hDAAO or pLG72-ECFP indicate that the two fusion proteins are targeted to different cellular destinations, similarly to that reported for COS7 cells transfected with pLG72 (Kvajo et al., 2008).

To further confirm the subcellular localization of pLG72, mitochondria were immunoprecipitated using anti-TOM22 (Translocase of the Outer mitochondrial Membrane) antibodies and MACS $®$ technology. The immunoprecipitated fractions corresponding to U87 and U87 pLG72-ECFP cells were analyzed by Western blot using anti-GFP and anti-ERAB (Endoplasmic Reticulum-associated Amyloid Beta-peptidebinding, a marker of mitochondrial matrix) antibodies and detected a specific pLG72 signal in the immunoprecipitated intact mitochondria of U87 cells stably expressing pLG72, see Fig. $2 \mathrm{H}$.

hDAAO "interacts" with pLG72 before being targeted to its final (peroxisomal) destination

In order to verify whether the hDAAO-pLG72 interaction is dependent on a spatiotemporal stimulus (Sacchi et al., 2008), U87 pLG72-ECFP cells were transiently transfected with the pEYFP-hDAAOC3 expression vector and analyzed by confocal microscopy at different time points upon transfection. After $24 \mathrm{~h}$, the EYFP-hDAAO-associated fluorescence is spread throughout the cells (Fig. 3, panel A left) and is more intense in the perinuclear region where it clearly colocalizes with the signal corresponding to pLG72-ECFP. Over time, the fluorescence signal associated with EYFP-hDAAO shows a gradual compartmentalization of the chimeric flavoprotein: at $72 \mathrm{~h}$ after transfection the typical punctuate (peroxisomal) distribution of hDAAO is evident (bottom panel in Fig. 3A left). Interestingly, no time-dependent change in hDAAO signal distribution is observed in U87 cells transiently expressing hDAAO-EYFP (i.e. the enzyme form lacking the exposed peroxisomal targeting signal, see Supplementary materials). By comparing pLG72ECFP and EYFP-hDAAO signal distribution in cells at $72 \mathrm{~h}$ from transfection colocalization is only marginal: the overexpressed flavoprotein is initially cytosolic and is targeted to peroxisomes at later timepoints. The same trend in hDAAO localization and signal intensity is also observed in control U87 cells transfected with the same construct (Fig. 3B left) or with the pIRES-hDAAO vector for the expression of the untagged flavoprotein (Fig. 3A and B, right panels). The observed time course of hDAAO peroxisomal import is similar to that observed for other peroxisomal complex proteins, e.g. the peroxisomal amount of human epoxide hydroxylase in $\mathrm{CHO}$ cells increased up to $72 \mathrm{~h}$ from transient transfection (Luo et al., 2008). Furthermore, a different time course of signal colocalization is apparent for U87 pLG72-ECFP cells

Fig. 2. Subcellular localization of hDAAO and pLG72 by immunostaining experiments in U87 stably transfected cells. A-B) The EYFP-hDAAO and untagged hDAAO pattern distribution clearly overlaps with PMP70 staining, indicating that the fusion protein is largely present inside peroxisomes. C-G) A clear overlapping of pLG72-ECFP or the pLG72-FLAG corresponding signal is observed when the cells are stained using a mitochondrial marker (Mito), suggesting that pLG72 is, for the most part, targeted to these organelles (see panels $\mathrm{C}$ and F). No significant overlapping in signal distribution was observed between the pLG72-ECFP or pLG72-FLAG signal and PMP70 (D and G) or $58 \mathrm{~K}(\mathrm{E})$ stainings, ruling out the presence of this chimeric protein in peroxisomes or Golgi apparatus, respectively. Bar $=3 \mu \mathrm{m} . \mathrm{H}$ ) In U87 pLG72-ECFP cells the subcellular localization of the chimeric protein has been further studied by immunoprecipitation experiments using anti-TOM22 magnetical Microbeads and the MACS Technology. Western blot analysis confirmed the presence of pLG72-ECFP in the eluted mitochondrial fraction: a specific anti-GFP signal is apparent in the immunoprecipitated sample (lane 1, compared to the corresponding control using untransfected U87 cells in lane 2). The nearly complete isolation of intact mitochondria is verified by an anti-ERAB antibody: the correspondent immunorecognition signal is detected in the immunoprecipitated samples (lanes 1 and 2 ) as well as in the starting cell lysates samples (lanes 5 and 6 ), but not in the recovered column flow through fractions (lanes 3 and 4). 
A

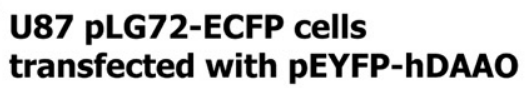

U87 pLG72-ECFP cells transfected with pEYFP-hDAAO

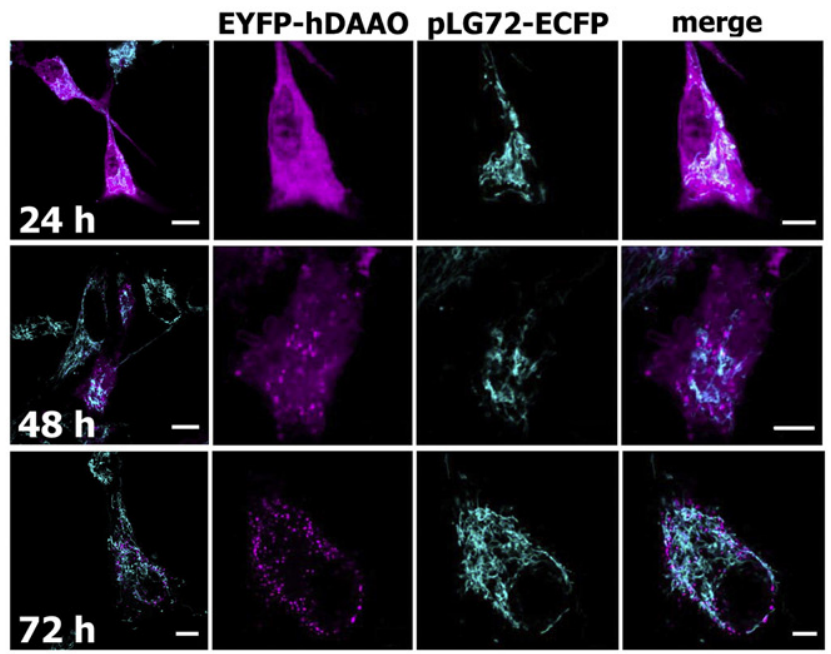

U87 pLG72-ECFP cells transfected with pIRES-hDAAO

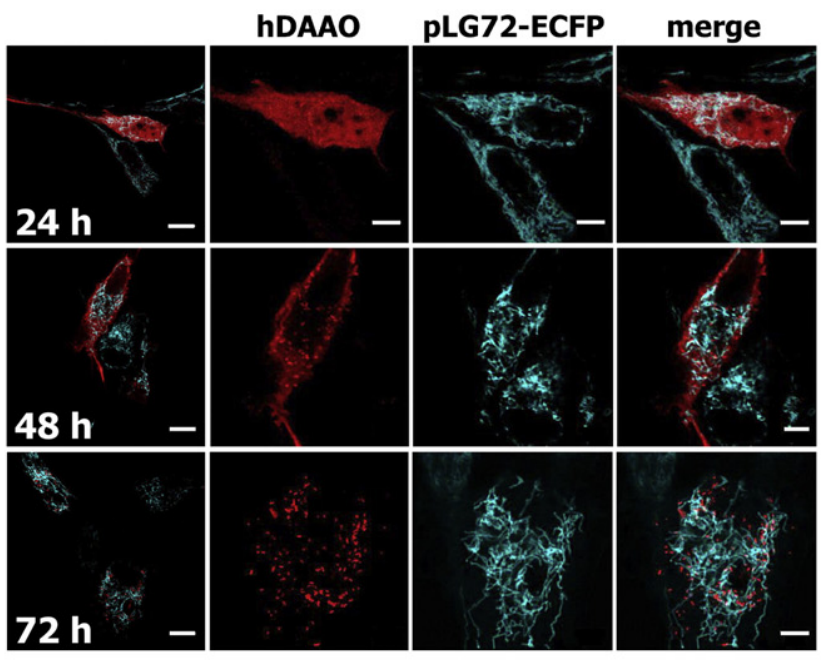

B

U87 cells transfected with pEYFP-hDAAO

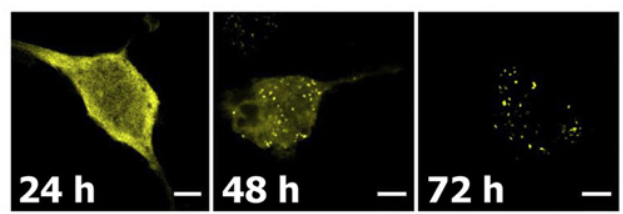

U87 transfected with pIRES-hDAAO

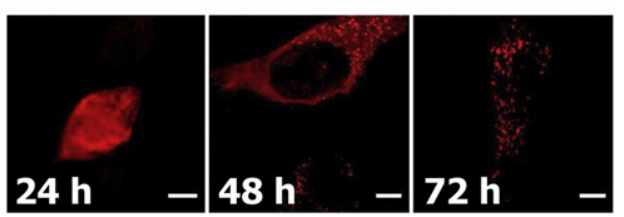

C

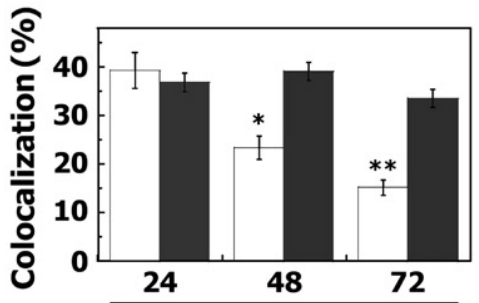

Hours upon transfection

Fig. 3. The time course of EYFP-hDAAO and hDAAO subcellular localization shows that pLG72-ECFP and the newly expressed hDAAO "transitorily" colocalize in U87 pLG72-ECFP cells transfected with pEYFP-hDAAO or pIRES-hDAAO. A) Confocal microscopy analyses were performed on U87 pLG72-ECFP cells transiently transfected with pEYFP-hDAAO-C3 (left panels) or pIRES-hDAAO (right panels) constructs and fixed at different time points upon transfection. At $24 \mathrm{~h}$ after transfection (top panels), pLG72-ECFP fluorescence pattern largely overlaps with the signals corresponding to EYFP-hDAAO (left) and hDAAO (right), which are diffusely distributed in the cytosol throughout the cell; a significant colocalization signal is observed in both cases, as depicted in the merge panels. At $48 \mathrm{~h}$ (central panels), EYFP-hDAAO and hDAAO signals start to appear compartimentalized and a decrease in the colocalization with pLG72-ECFP is apparent (see merge panels). The typical punctuate distribution of EYFP-hDAAO fluorescence is observed at $72 \mathrm{~h}$ after transfection together with a weak signal colocalization between pLG72 and hDAAO (bottom panels). Bar is $10 \mu \mathrm{m}$ ( $5 \mu \mathrm{m}$ in "merge" panels). To make easier signals comparison, EYFP-DAAO fluorescence is depicted in magenta (left panels). In pIRES-hDAAO transfected cells hDAAO is stained with a sheep anti-DAAO and a donkey anti-sheep Alexa546 conjugated antibodies. B) U87 Control cells transiently transfected with the pEYFP-hDAAO-C3 (left) and the pIRES-hDAAO (right) constructs and analyzed at 24-72 h upon transfection show the same trend in EYFP-hDAAO and hDAAO signal distribution as observed in U87 pLG72-ECFP transfected cells (see the corresponding panels in A). C) The time course of signal colocalization between hDAAO and pLG72 is different for U87 pLG72-ECFP cells transiently transfected with EYFP-hDAAO (white bars) or hDAAO-EYFP (black bars) expression vectors. The colocalization was determined from confocal microscopy fluorescence images as reported in "inset" panels $(\mathrm{n}=5-10)$. The change in colocalization value for EYFPhDAAO and pLG72-ECFP is statistically significant at both $48 \mathrm{~h}\left({ }^{*} \mathrm{p}<0.004\right)$ and $72 \mathrm{~h}\left({ }^{* *} \mathrm{p}<0.001\right)$. In contrast, no statistically significant modification in the colocalization signal is observed for hDAAO-EYFP.

transiently transfected with plasmids encoding for EYFP-hDAAO or hDAAO-EYFP (Fig. 3C and Suppl. Fig. S2): the signal colocalization is not significantly altered up to $72 \mathrm{~h}$ in cells expressing cytosolic hDAAOEYFP, whereas for cells expressing EYFP-hDAAO this value decreases from $\sim 39 \%$ at $24 \mathrm{~h}$ to $14 \%$ at $72 \mathrm{~h}$ (Fig. 3C). The greatest level of hDAAOpLG72 colocalization is observed when the amount of newly synthesized EYFP-hDAAO in cytosol is maximal, before it targets peroxisomes.

The inferred cellular protein-protein interaction was further verified by FRET analysis on U87 pLG72-ECFP cells transiently transfected with the pEYFP-hDAAO-C3. In Fig. 4, pLG72-ECFP and EYFP-hDAAO signal distribution is shown in CFP and YFP panels, respectively, while the raw signal due to the energy transfer is reported in FRET panels. The raw signals were corrected to remove the bleedthrough generated by spectral overlap between donor (ECFP) and acceptor (EYFP) under the FRET filter combination. The resulting digitalized NFRET images are shown in the right column in Fig. 4 (NFRET panels), together with the average parameters calculated in five different regions within each cell. At $24 \mathrm{~h}$ upon transfection, FRET signals closely resemble those for pLG72-ECFP (see Fig. 4A). The calculated NFRET value in different cells ranges between $0.408 \pm$ 0.0073 and $0.463 \pm 0.0069$ (mean \pm standard error, $\mathrm{n}=6$ ), yielding to a mean value of $0.436 \pm 0.00647$ (mean \pm standard error, $n=12$ ) and 

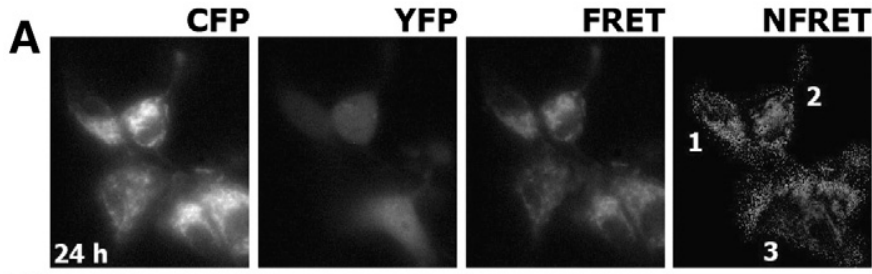

$1=0.46 \pm 0.016$

$2=0.41 \pm 0.033$

B
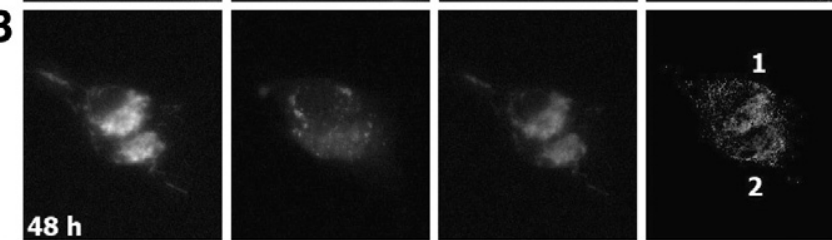

$3=0.45 \pm 0.015$

C
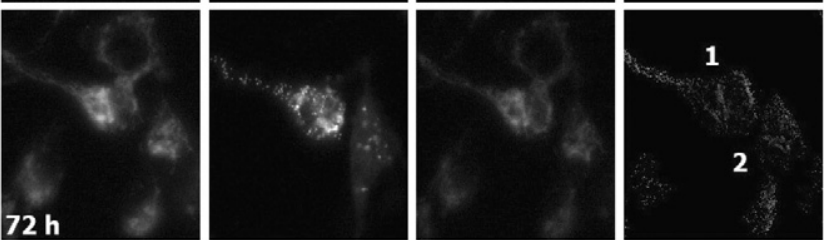

$1=0.36 \pm 0.03$

$2=0.32 \pm 0.056$

D

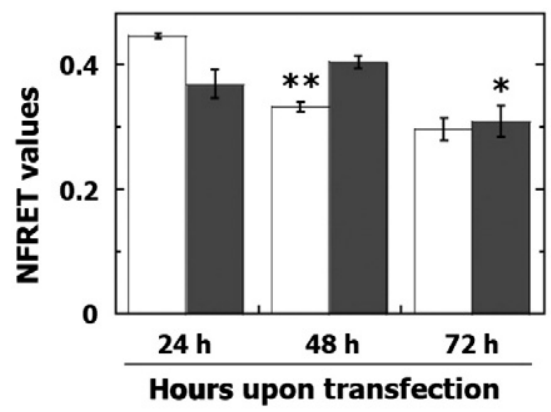

Fig. 4. FRET analysis confirms EYFP-hDAAO and pLG72-ECFP cellular interaction. U87 pLG72-ECFP cells were transiently transfected with the pEYFP-hDAAO-C3 construct. Cells were analyzed at $24 \mathrm{~h} \mathrm{(A),48} \mathrm{h} \mathrm{(B),} \mathrm{and} 72 \mathrm{~h}(\mathrm{C})$ upon transfection by a fluorescent microscope equipped with a CCD camera and a three-filter setup: CFP filter (exc. $=430 \mathrm{~nm}$, em. $=$ $470 \mathrm{~nm}$, CFP panel); YFP filter (exc. $=500 \mathrm{~nm}$, em. $=535 \mathrm{~nm}$, YFP panel); and FRET filter (exc. $=430 \mathrm{~nm}$, em. $=535 \mathrm{~nm}$, FRET panel). The raw images were corrected to remove the contribution of the bleedthrough signal, yielding the NFRET signal distribution (NFRET panel). The NFRET parameters calculated in five different areas for each analyzed cell $(n=5-10)$ are reported $\pm S D$ (standard deviation) and indicate protein-protein interaction. D) The plot of the time course of NFRET mean values ( \pm standard error) determined for U87 pLG72-ECFP cells transiently expressing EYFP-hDAAO (white bars, $\mathrm{n}=6-13$ ) or hDAAO-EYFP (black bars, $\mathrm{n}=5-8$ ) shows that a decrease in signal colocalization is apparent at shorter times with the previous enzyme form. The change in NFRET parameter was demonstrated to be statistically significant for cells expressing EYFP-hDAAO at 48 vs. $24 \mathrm{~h}$ $\left({ }^{* *} \mathrm{p}<0.001\right)$ and for cells expressing hDAAO-EYFP at 72 vs. $48 \mathrm{~h}\left({ }^{*} \mathrm{p}<0.015\right)$.

thus supporting the interaction between the two human proteins. In order to avoid the possibility of false positive signals, two control experiments were performed by transfecting EYFP in the U87 cell line stably expressing pLG72-ECFP as well as by cotransfecting ECFP with EYFP-hDAAO in the U87 cell line. Calculated NFRET values give $0.0359 \pm 0.0053$ and $0.0348 \pm 0.0096$ (mean \pm standard error, $\mathrm{n}=12$ ), respectively, suggesting that the proteins of our interest do not aspecifically interact with widespread expressed ECFP or EYFP. Based on the mitochondrial localization of pLG72, see above and (Benzel et al., 2008; Kvajo et al., 2008), we now suggest that pLG72 and hDAAO could (transiently) interact on the mitochondrial surface. The calculated NFRET mean values are appreciably lower at longer times (the decrease is statistically significant between 24 and $48 \mathrm{~h}$, white bars in Fig. 4D): targeting peroxisomes of overexpressed hDAAO decreased interaction with pLG72. A clear colocalization between hDAAO and pLG72 is also apparent using the plasmid encoding for cytosolic hDAAO-EYFP: notably, NFRET mean values slightly increase between 24 and $48 \mathrm{~h}$ after transfection (black bars in Fig. 4D) because this chimeric form of the flavoprotein is not competent in peroxisomal targeting.

To further substantiate the "transient" interaction between hDAAO and pLG72, we analyzed the distribution time course for the flavoprotein in soluble (cytosolic) and unsoluble fractions of U87 or U87 pLG72-ECFP cells transiently transfected with pEYFP-hDAAO-C3 plasmid by means of Western blot and activity assays. In U87 control cells at $24 \mathrm{~h}$ from transient transfection $24.9 \pm 3.7 \%$ of EYFP-hDAAO is present in the soluble fraction, a value statistically significantly higher than for cells simultaneously and stably expressing pLG72 $(18.8 \pm 0.5 \%)$, see Fig. $5 \mathrm{~A}, \mathrm{~B}$ (top panels). The amount of hDAAO in the soluble fraction increases at longer times, reaching similar levels at $48 \mathrm{~h}$ after EYFP-hDAAO transfection for both U87 and U87 pLG72ECFP cells (35.5 vs. $36.3 \%$, respectively). This experiment also demonstrates that cytosolic hDAAO is active: a rough calculation based on the amount of hDAAO (as estimated from Western blot analysis) reveals that its specific activity is similar for soluble vs. membrane-bound hDAAO. Indeed, the values at $24 \mathrm{~h}$ from transfection indicate that overexpressed pLG72 binds the newly synthesized hDAAO, thus affecting the amount of hDAAO present in the cytosolic fraction, an effect that is no longer apparent at longer times probably because the binding ability of pLG72 is saturated.

We finally verified if pLG72-interaction alters the stability (half life) of hDAAO at cellular level. We analyzed by Western blot the time course of hDAAO and pLG72 levels in U87 and U87 pLG72-ECFP cells transiently transfected for EYFP-hDAAO and that have been treated or not with cycloheximide (a potent inhibitor of protein synthesis) at $24 \mathrm{~h}$ from transfection. The amount of hDAAO following EYFP-hDAAO transfection is rather stable in U87 cells treated or not with cycloheximide (not shown), while its amount decreases in U87 pLG72-ECFP cells upon block 


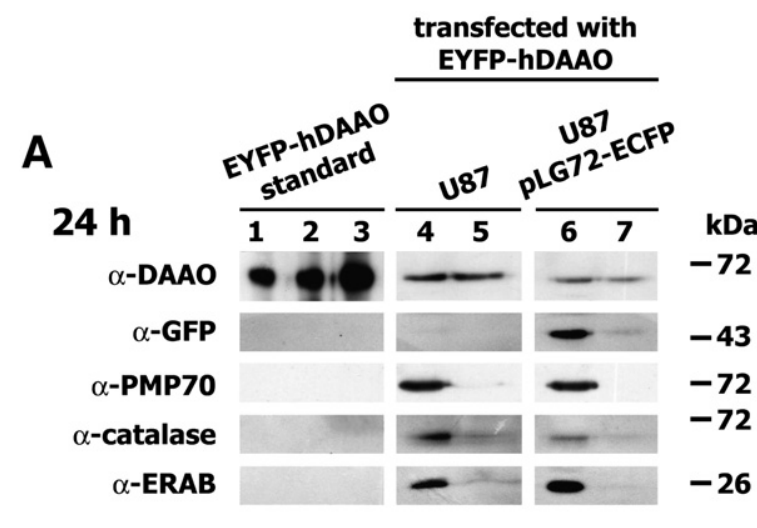

B
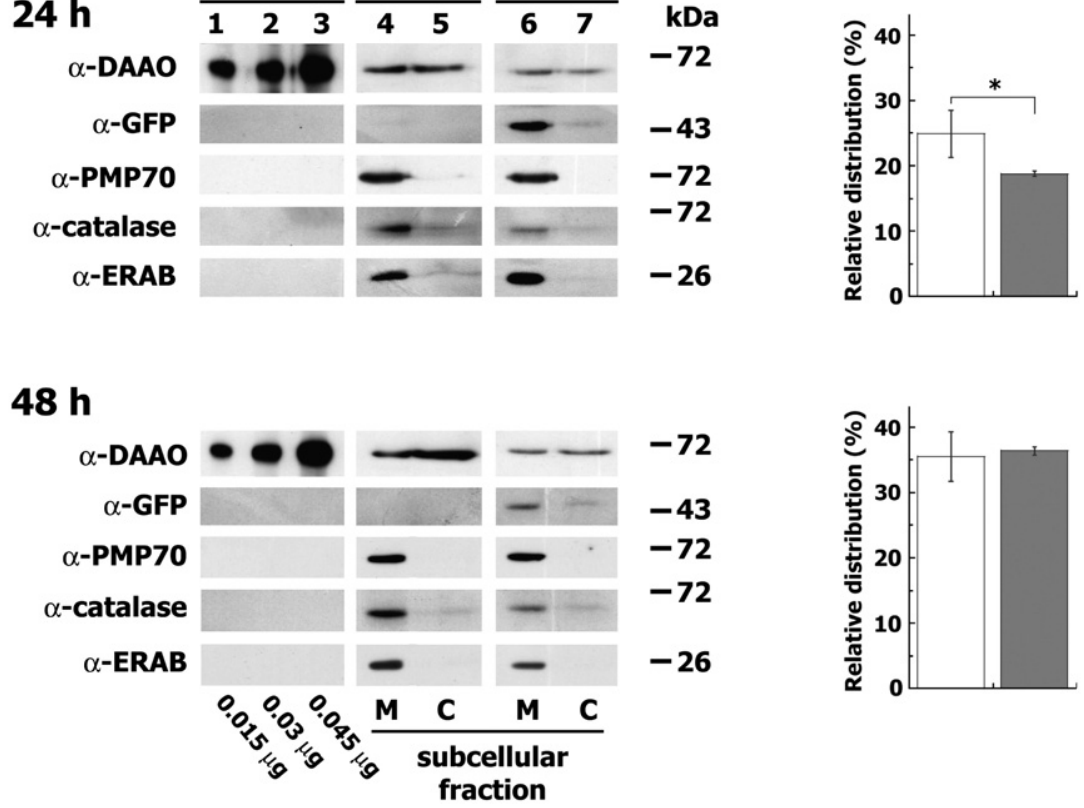

Fig. 5. Cellular relative distribution of EYFP-hDAAO in transiently transfected U87 and U87 pLG72-ECFP cells. A) Western blot analysis shows that in U87 pLG72-ECFP cells the amount of EYFP-hDAAO in the cytosolic subcellular fraction is lower than in U87 control cells at $24 \mathrm{~h}$ after transfection. The presence of intact organelles in the membrane fraction is verified through the detection of anti-PMP70, anti-catalase (for peroxisomes), and anti-ERAB (for mitochondria) immunorecognition signals in the different samples. Lanes 1-3: EYFP-hDAAO standard protein $(0.015,0.03,0.045 \mu \mathrm{g}$, respectively). Lanes $4-5$ and 6-7: EYFP-hDAAO transfected U87 and U87 pLG72-ECFP cells, respectively. M $=$ membrane fraction; $\mathrm{C}=$ cytosolic fraction. For sake of comparison, in each lane the same amount of total proteins $(60 \mu \mathrm{g})$ was loaded, which corresponds to the following amounts of cells: U87 cells at $24 \mathrm{~h}, \mathrm{M}=3.0 \times 10^{5}$ cells and $\mathrm{C}=9.8 \times 10^{5}$ cells; U87 pLG72-ECFP cells at $24 \mathrm{~h}, \mathrm{M}=1.7 \times 10^{5}$ cells and $\mathrm{C}=5.2 \times 10^{5}$ cells; U87 cells at $48 \mathrm{~h}, \mathrm{M}=1.0 \times 10^{5}$ cells and $\mathrm{C}=3.8 \times 10^{5}$ cells; U87 pLG72-ECFP cells at $48 \mathrm{~h}, \mathrm{M}=1.3 \times 10^{5}$ cells and C $=3.2 \times 10^{5}$ cells. B) Relative amount of hDAAO present in the soluble fraction of U87 cells (white bars) and U87 pLG72ECFP cells (gray bars) transiently transfected with EYFP-hDAAO. The data are the average ( \pm standard deviation) of values determined from Western blot analysis (see also panel A) and Amplex Red activity assay (determined using $7.5 \times 10^{5}$ cells). At $24 \mathrm{~h},{ }^{*} \mathrm{p}<0.001$.

of protein synthesis (Fig. 6A, left). Concerning U87 pLG72-ECFP cells, a quick decrease in pLG72 concentration is apparent upon block of protein synthesis (Fig. 6B, right). From the cycloheximide-treatment results, we conclude that the binding of a short-life protein such as pLG72 might (negatively) affect the half life of (cytosolic) hDAAO.

\section{Cellular D-serine levels}

We analyzed the time course of D-serine concentration on U87 and U87 pLG72-ECFP cells transiently transfected for EYFP-hDAAO. As depicted in Fig. 6A, both the D-serine concentration and the D-/L-serine ratio are significantly higher in cells stably expressing pLG72 (5.8 vs. $4.2 \%$ ), thus further confirming the inhibitory effect of this protein on hDAAO activity (Sacchi et al., 2008). The time course of D-serine concentration following hDAAO transient expression is different in U87 control vs. U87 pLG72-ECFP cells, as is the D-serine concentration at $24 \mathrm{~h}$ (Fig. 6B): the binding of pLG72 to newly synthesized hDAAO decreases the flavooxidase activity and limits the decrease in D-serine concentration. However, similar D-/L-serine ratios ( $2 \%)$ are observed at times $\geq 72 \mathrm{~h}$ for both cell systems: this observation indicates that this value at the cellular level is controlled by further enzymatic activities (i.e., by the SR activity that reversibly converts D- and L-serine).

\section{Discussion}

In neurobiology the existence (and role) of gliotransmission is the subject of important debate (Smith, 2010). On one side of the argument,
D-serine is considered a "new" neuromodulator released by glial and neuronal cells following stimulation of AMPA/kainate receptors by glutamate released from neurons (Martineau et al., 2006; Oliet and Mothet, 2009). Cellular concentrations of D-serine depend on both SR and DAAO enzymatic activity. While different mechanisms regulate brain SR (Baumgart and Rodríguez-Crespo, 2008; Pollegioni and Sacchi, 2010), less is known about hDAAO. Recently, we demonstrated in vitro that pLG72 interacts with hDAAO to yield an 200-kDa complex and a faster enzyme inactivation (Sacchi et al., 2008). By transiently transfecting human U87 glioblastoma cells with expression vectors encoding for EGFP-tagged hDAAO or pLG72 proteins we showed that hDAAO has a major role in controlling cellular D-serine levels and confirmed the proposal that in vivo pLG72 acts as an endogenous negative modulator of hDAAO (Sacchi et al., 2008). Indeed, this work identified hDAAO and pLG72 in the same astrocytes of the human cerebral cortex and, concerning the subcellular localization of hDAAO and pLG72, showed that only $5 \%$ of the cells displayed overlapping signals (Sacchi et al., 2008). This result suggested that pLG72 interaction with hDAAO is probably driven by specific, unknown spatiotemporal stimuli.

By means of immunohistochemistry and organelle immunoprecipitation we have now confirmed that pLG72 has a mitochondrial localization, as previously reported for COS7 transfected cells and for glioma U251 and primary neurons (Benzel et al., 2008; Kvajo et al., 2008). However, a vescicular distribution of mitochondria in G72transfected cells, a modified morphological pattern related to mitochondrial fragmentation (Kvajo et al., 2008), was not apparent in U87 pLG72-ECFP cells. The discrepancy between our results and 
A
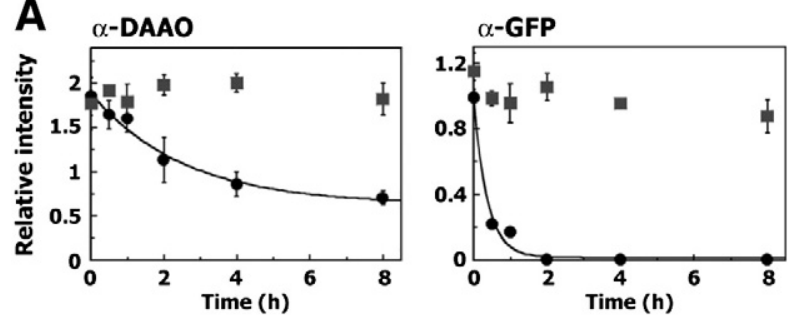

B

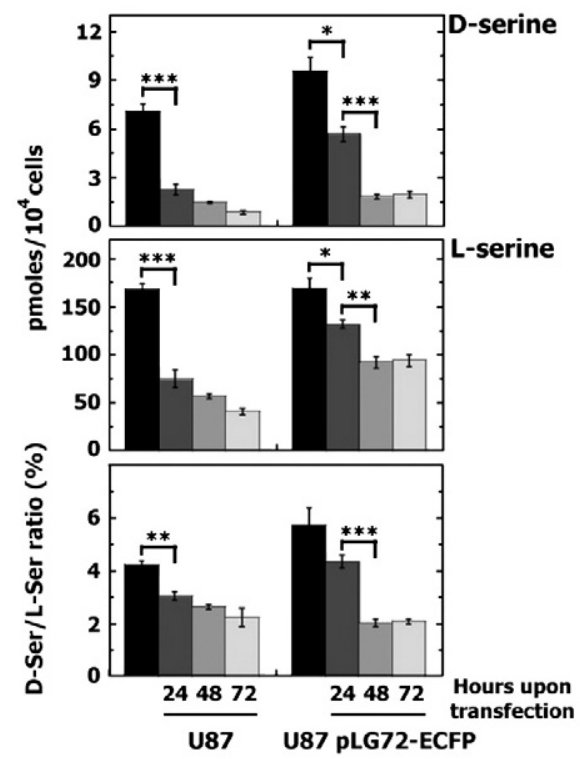

C

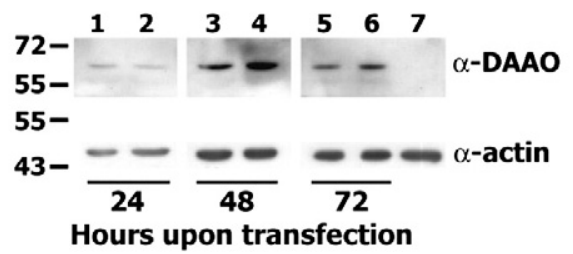

Fig. 6. Effect of the overexpression of EYFP-hDAAO on hDAAO, pLG72 and D-serine cellular levels in transiently transfected cells. A) U87 pLG72-EGFP cells transiently transfected with pEYFP-hDAAO (at $24 \mathrm{~h}$ ) were treated with (circles) or not (squares) $100 \mu \mathrm{g} / \mathrm{mL}$ cycloheximide (CHX) at time zero. Cells were harvested at the times shown, separated by SDS-PAGE and immunoblotted. Values are the average \pm standard deviation $(n=4)$, normalized to actin. Left panel: immunorecognition using antiDAAO antibodies; right panel: immunorecognition using anti-GFP antibodies, to detect pLG72. B) HPLC analysis of D- and L-serine concentrations in transiently transfected U87 and U87 pLG72-ECFP cell extracts at different times upon transfection. D-serine and L-serine levels in the transfected cells (gray bars) are compared to those detected in control cells (U87 and U87 pLG72-ECFP untransfected cells respectively, black bars). The measured levels of both enantiomers and the calculated D-serine/L-serine ratio are higher in U87 pLG72-ECFP, confirming the negative effect on hDAAO activity proposed for pLG72-ECFP. ${ }^{*} \mathrm{p}<0.005 ;{ }^{* *} \mathrm{p}<0.001 ;{ }^{* * *} \mathrm{p}<0.0001$. C) Western blot analysis confirms the expression of EYFP-hDAAO protein both in U87 (lanes 1, 3,5) and U87 pLG72-ECFP cells (lanes 2, 4, 6), and allows an estimation of the cellular level of the chimeric protein (an equal amount of sample-corresponding to $5 \times 10^{4}$ cells-has been loaded): the maximum level of expression is observed at $48 \mathrm{~h}$ and a similar amount of EYFP-DAAO is expressed in the two cell types at different times upon transfection. Lane 7: U87 control cells.

those from (Kvajo et al., 2008) could arise from the different chimeric pLG72 proteins used, although in both cases the tag was added at the C-terminus of the protein to preserve the $\mathrm{N}$-terminal end that contains the putative mitochondrial targeting sequence. A possible warning that the myc-tagged pLG72 conformation has been altered (Kvajo et al., 2008) as compared to the native one is made apparent by the failure to coimmunoprecipitate the hDAAO-pLG72 complex from cotransfected COS7 cells and to inhibit cellular hDAAO following exogenous myc-pLG72 expression. Our results, based on U87 cells stably expressing pLG72 and transiently transfected with hDAAO, demonstrate that colocalization of the two proteins is transitory. The colocalization is most apparent at $24 \mathrm{~h}$ after hDAAO transfection, when the fluorescence signal corresponding to the flavoenzyme is largely diffused in cytosol while the associated FRET signal shows a distribution pattern closely resembling the one typically associated with mitochondria and pLG72. At this time the amount of hDAAO in the membrane-bound fraction is higher in cells overexpressing pLG72 than in U87 control cells (Fig. 5), suggesting sequestration of newly synthesized hDAAO on the surface of mitochondria because of pLG72 interaction. The pLG72-hDAAO colocalization is lost later, in conjunction with a punctuate distribution of hDAAO, indicating that the flavoprotein has been correctly targeted to peroxisomes.

As stated by (Verrall et al., 2010) "the subcellular distribution of $D A A O$ is relevant to the question of how it 'sees' its substrates. For DAAO located outside the peroxisomes, accessibility of DAAO to its substrates would likely not be an issue". The present work does not clarify the origin of the spatiotemporal stimulus that induces the interaction between pLG72 and hDAAO, but clearly shows that the newly synthesized hDAAO interacts with pLG72. Indeed, we demonstrate that cytosolic hDAAO is active and its specific activity resembles that of the peroxisomal enzyme, and that under the experimental conditions used a short-life protein such as pLG72 negatively affects the half life of hDAAO (Fig. 6A). Since peroxisomal proteins are known to acquire a conformation close to the final one in the cytosol before being targeted to their final destination (peroxisomes are capable of importing folded proteins and mature oligomers), pLG72 binding to hDAAO on the cytosolic side of mitochondrial membranes (and ensuing enzyme inactivation and faster degradation) plays a protective role against DAAO-induced depletion of cytosolic D-serine (Fig. 6) and in case of cellular oxidative stress.

In conclusion, since hypofunction of the NMDAr has been implicated in the pathophysiology of schizophrenia, these receptors represent a promising therapeutic target for psychiatric illness, see (Labrie and Roder, 2010). Compounds that directly activate the glycine/D-serine site of NMDAr or inhibit glycine transport have demonstrated beneficial effects in preclinical models and clinical trials. Future pharmacological approaches for schizophrenia treatment may involve targeting enzymes that affect D-serine metabolism, and thus the processes underlying hDAAO regulation (e.g., the elucidation of mechanisms of protein expression/degradation, the post-translational modifications that affect its functionality, as well as further binding partners, etc.) related to specific cellular scenarios will need to be fully elucidated.

\section{Experimental methods}

\section{Molecular cloning}

The pEGFP-hDAAO-C3 construct (Sacchi et al., 2008) was used as a template for subcloning hDAAO cDNA into the pEYFP-C3 and pEYFPN1 mammalian expression vectors (Clontech Laboratories): in this way hDAAO can be expressed upstream and downstream of the enhanced yellow fluorescent protein (EYFP). The cDNA encoding for pLG72 was purchased as a full ORF clone from imaGenes (IRAMp995E0829Q) and subcloned in pECFP-C3 and pECFP-N1 plasmids, allowing pLG72 to be expressed upstream and downstream of the enhanced cyan fluorescent protein (ECFP), respectively. The latter construct was used as a template for subcloning pLG72 cDNA into the pCMV-SC-CF vector (Strataclone Mammalian Expression Vector System, Stratagene), designed for high-level expression of epitopetagged proteins: three copies of the FLAG (DYKDDDDK) epitope were fused to the C-terminal of the overexpressed pLG72. Indeed, hDAAO cDNA was subcloned in the pcDNA3 (pcDNA3-hDAAO, Invitrogen) 
and pIRESneo3 (pIRES-hDAAO, Clontech Laboratories) expression vectors, in order to produce the untagged flavoprotein.

\section{Cell culture and transfection}

The U87 human glioblastoma cells (ATCC) were maintained in DMEM supplemented with $10 \%$ fetal bovine serum, $1 \mathrm{mM}$ sodium pyruvate, $2 \mathrm{mM}$ L-glutamine, penicillin/streptomycin, and amphotericin $\mathrm{B}$ (Euroclone) at $37^{\circ} \mathrm{C}$ in a $5 \% \mathrm{CO}_{2}$ incubator as reported in (Sacchi et al., 2008) and transfected using the FuGENE HD transfection reagent (Roche) and $2 \mu \mathrm{g}$ of pEYFP-hDAAO-C3 or -N1, pECFP-pLG72-C3 or -N1, pcDNA3-hDAAO, pIRES-hDAAO or pLG72-FLAG constructs. Protein expression levels were monitored either by using a fluorescence microscope (Olympus IX51) equipped with a FITC filter to detect the emission signal associated with the fluorescent tag, or by Western blot analysis using anti-FLAG, anti-EGFP, or anti-hDAAO specific antibodies. The transfected cells were used for further experiments or to select stable clones, adding $0.4 \mathrm{mg} / \mathrm{mL}$ G418 to the growth medium.

Cellular D- and L-serine levels were determined as stated in (Sacchi et al., 2008). Briefly, $2.5 \times 10^{5}$ cells of U87 and U87-pLG72-ECF cells transiently transfected with EYFP-hDAAO expression plasmid were resuspended in $1 \mathrm{~mL}$ of ice-cold 5\% trichloroacetic acid, sonicated, and centrifuged for $45 \mathrm{~min}$ at $13,000 \mathrm{rpm}$. The soluble fraction was extracted with water-saturated ether, neutralized, and derivatized with $o$-phthaldialdehyde/N-acetyl-L-cysteine in borate buffer. D- and L-serine were resolved by HPLC chromatography on a 5- $\mu \mathrm{m}$ Waters C8 $(4.6 \times 250 \mathrm{~mm})$ reversed-phase column; amounts were determined using a calibration curve obtained with standard D- and L-serine. The analyses were replicated five times for each condition and statistical analyses were performed using Kaleidagraph software (Synergy Software). Variation between groups was evaluated by one-way ANOVA, and post-hoc significance tests were performed using a Student's $t$ test. Significance was assessed at $\mathrm{p}<0.05$.

\section{Subcellular fractionation}

A cytosolic cellular fraction (containing soluble proteins) and an insoluble fraction enriched in proteins bound to membranes or located inside organelles were prepared by differential centrifugation (Graham, 2001). Briefly, $1.2 \times 10^{7}$ cells were suspended in $0.4 \mathrm{~mL}$ of homogenation buffer (10 mM Tris- $\mathrm{HCl} \mathrm{pH} 8.0,0.25 \mathrm{M}$ sucrose), protease inhibitors ( $2 \mu \mathrm{M}$ leupeptin, $1 \mu \mathrm{M}$ pepstatin, $500 \mu \mathrm{M}$ PMSF), $40 \mu \mathrm{M}$ FAD, $10 \mu \mathrm{g} / \mathrm{ml}$ DNAse, and $0.1 \%$ ethanol were added, and then the preparation was homogenized with a Teflon potter. The homogenate was centrifuged at $1000 \times \mathrm{g}$ for $10 \mathrm{~min}$ at $4{ }^{\circ} \mathrm{C}$; the pellet was suspended in $0.4 \mathrm{~mL}$ of homogenation buffer and the previous step was repeated; and the combined surnatants were then centrifuged at $15,000 \times \mathrm{g}$ for $25 \mathrm{~min}$ at $4{ }^{\circ} \mathrm{C}$. The final surnatant (cytosolic fraction) and the combined pellets (membrane fraction) were used for Western blot analysis and DAAO activity assay. DAAO activity was measured by using the Amplex ${ }^{\circledR}$ UltraRed assay kit (Invitrogen) based on the detection of $\mathrm{H}_{2} \mathrm{O}_{2}$ by the peroxidasemediated oxidation of the fluorogenic Amplex UltraRed dye as stated in (Sacchi et al., 2008). Briefly, the cytosolic and the resuspended membrane fraction were diluted $1: 2$ in the activity assay solution containing $50 \mu \mathrm{M}$ Amplex UltraRed, $0.2 \mathrm{U} / \mathrm{mL}$ horseradish peroxidase, $10 \mathrm{mM} \mathrm{NaN}_{3}, 10 \mu \mathrm{M} \mathrm{FAD}$, and $50 \mathrm{mM}$ D-serine and incubated for $60 \mathrm{~min}$ at room temperature in the dark. The reactions were blocked by adding $20 \mu \mathrm{L}$ of Amplex UltraRed stop reagent and the fluorescence emission at $590 \mathrm{~nm}$ was measured. For each sample a control without the substrate D-serine was prepared: DAAO activity was expressed as the difference in fluorescence emission between sample and control assay mixtures. Statistical analyses were performed as reported above.

\section{Mitochondria isolation}

A subcellular fraction enriched in intact mitochondria was prepared from U87 and U87 pLG72-ECFP cells by using the MACS Technology (Mitochondria isolation kit, Miltenyi Biotec) and magnetically labeling the organelles with an anti-TOM22 antibody. The same experiment was also carried out on cells collected at $24 \mathrm{~h}$ from transient transfection with pEYFP-hDAAO plasmid. Briefly, $1.1 \times 10^{7}$ cells were collected and washed with $10 \mathrm{~mL}$ ice-cold PBS pH 7.2: the cells were then resuspended in $1 \mathrm{~mL}$ ice-cold "lysis buffer" to which was added protease inhibitors $(2 \mu \mathrm{M}$ leupeptin, $1 \mu \mathrm{M}$ pepstatin, $500 \mu \mathrm{M}$ PMSF), and the preparation was then homogenized by passing it through a $0.2 \mu \mathrm{m}$ needle 50 times. Then $9 \mathrm{~mL}$ of ice-cold PBS and $50 \mu \mathrm{L}$ of anti-TOM22 magnetic beads were added; this was incubated for $1 \mathrm{~h}$ at $4{ }^{\circ} \mathrm{C}$ before magnetically separating the mitochondria on the MACS column rinsed with "separation buffer" and then placed in the MACS separator. The column was washed with $3 \times 3 \mathrm{~mL}$ of separation buffer and removed from the separator. The magnetically labeled mitochondria were flushed out by adding $1.5 \mathrm{~mL}$ of separation buffer.

\section{Immunoblot and immunofluorescence}

Both stable and transiently transfected cells were resuspended in SDS-PAGE sample buffer to reach 2500 cells/ $\mu \mathrm{L}$ and $20 \mu \mathrm{L}$ of each sample was subjected to SDS-PAGE electrophoresis and Western blot analyses (Sacchi et al., 2008). The polyvinylidene difluoride membranes (Immobilon-P, Millipore) were incubated $2 \mathrm{~h}$ at room temperature or overnight at $4{ }^{\circ} \mathrm{C}$ in a blocking solution containing $4 \%$ dried milk in Tris-buffered saline (TBS; $10 \mathrm{mM}$ Tris-HCl, $\mathrm{pH}$ 8.0, $0.5 \mathrm{M} \mathrm{NaCl}$ ) to which $0.1 \%$ Tween-20 (TTBS) was added and then incubated for $1.5 \mathrm{~h}$ at room temperature with primary antibodies. Membranes were then washed extensively in TTBS containing $2 \%$ dried milk and incubated for $1 \mathrm{~h}$ at room temperature with specific peroxidase-conjugated immunoglobulins. The immunoreactivity signals were detected by enhanced chemiluminescence (ECL plus, GE Healthcare) using the following primary antibodies: rabbit polyclonal anti-hDAAO (1:5000, Davids Biotecnologie); mouse monoclonal antiGFP (1:200), mouse monoclonal anti-ERAB (1:500), and goat polyclonal anti- $\alpha$-tubulin (1:200), all from Santa Cruz Biotechnology; rabbit polyclonal anti-catalase (1:5000, Abcam); rabbit polyclonal anti-PMP70 and anti-actin (1:200, Sigma).

To investigate the stability at the cellular level of hDAAO and pLG72, U87 and U87 pLG72-ECFP cells were transiently transfected with pEYFP-hDAAO as described above and were treated with $100 \mu \mathrm{g} /$ $\mathrm{mL}$ cycloheximide $24 \mathrm{~h}$ after transfection. At different time points, cells were harvested for Western blot analysis.

Immunostaining and confocal analyses were performed as stated in (Sacchi et al., 2008). Briefly, U87 cells were seeded on round glass coverslips $\left(2.5 \times 10^{5}\right.$ cells each $)$ and incubated for $24 \mathrm{~h}$ at $37^{\circ} \mathrm{C}$ and $5 \%$ $\mathrm{CO}_{2}$; subsequently the cells were extensively washed with PBS ( $10 \mathrm{mM}$ sodium phosphate dibasic, $2 \mathrm{mM}$ potassium phosphate monobasic, $137 \mathrm{mM} \mathrm{NaCl}$, and $2.7 \mathrm{mM} \mathrm{KCl}, \mathrm{pH} \mathrm{7.4)} \mathrm{and} \mathrm{fixed} \mathrm{with}$ $4 \% p$-formaldehyde and $4 \%$ sucrose in $0.1 \mathrm{M}$ sodium phosphate buffer, $\mathrm{pH} 7.4$, for $15 \mathrm{~min}$ at room temperature. Fixed U87 cells were permeabilized and the unspecific binding sites were blocked by a $30-$ min incubation at room temperature in PBS supplemented with $4 \%$ horse serum and $0.2 \%$ Triton X-100. The coverslips were incubated overnight at $4{ }^{\circ} \mathrm{C}$ with primary antibodies against specific markers of subcellular compartments: rabbit polyclonal anti-PMP70 for peroxisomes (1:400, Sigma); mouse monoclonal anti-58 K Golgi protein (1:200, from Abcam). Mitochondria were stained by using a specific anti-mitochondria antibody (1:25, Millipore). The pLG72 signal distribution was also confirmed in U87 pLG72-FLAG cells by staining with a rabbit polyclonal anti-FLAG antibody (1:25, Sigma). Untagged hDAAO was labeled using a sheep anti-hDAAO polyclonal and affinity 
purified antibody (1:20, from Rockland). Immunoreactivity was demonstrated with goat anti-rabbit FITC (1:100), donkey anti-sheep Alexa 488 and Alexa 546, donkey anti-rabbit Alexa 647 and donkey antimouse Alexa 546-conjugated antibodies (1:1000, Molecular Probes). Immunostained coverslips were imaged using an inverted laserscanning confocal microscope (TCS SP5, Leica Microsystems), equipped with a $63.0 \times 1.25 \mathrm{NA}$ plan apochromate oil immersion objective. Confocal image stacks were acquired using the Leica TCS software (with a sequential mode, if necessary) avoiding interference between each channel and without saturating any pixel, as reported in (Sacchi et al., 2008). Coverslips incubated omitting the primary antibodies were analyzed as negative controls. For colocalization analysis, z-optical sections were analyzed using the Leica SP5 software colocalization tools; the variation between groups was evaluated by one-way Anova. The pictures show z-stacks of ten consecutive optical sections.

\section{FRET image acquisition, analysis, and calculation}

Fluorescence images were acquired as reported in (Bossi et al., 2007) with a Retiga 2000R CCD camera (QImaging) mounted on a Zeiss Axiovert IM35 inverted microscope equipped with fluar $\times 40$ oilimmersion objective (Zeiss). Excitation was obtained by a $150-\mathrm{W}$ xenon arc lamp; excitation filters were $430 / 25 \mathrm{~nm}$ for ECFP and $500 / 20 \mathrm{~nm}$ for EYFP. A double dichroic filter (86002 BS), an optosplit image splitter (CAIRN Research) fitted with a 495DCLP beam splitter, and two emission filters at $470 / 30 \mathrm{~nm}$ and $535 / 30 \mathrm{~nm}$ were used to capture the two images (for ECFP and EYFP, respectively) on the same frame in the CCD chip. To minimize photobleaching effects an electronically driven shutter was interposed between the excitation filter and the dichroic mirror. All filters were from Chroma Technology Images; images were acquired under identical conditions and analyzed with Image pro Plus software (Media Cybernetics). NFRET images were constructed using the three-filter set method, according to (Xia and Liu, 2001). Relative background images were subtracted and independent thresholding was performed on the individual images to avoid imageprocessing artifacts. Donor and acceptor fluorescence bleedthrough was calculated from U87 cells stably expressing pLG72-ECFP or EYFPhDAAO alone and subtracted from the FRET image to obtain the net FRET $(\mathrm{nF})$ image. The $\mathrm{nF}$ image was then normalized by dividing it by the square root of the donor $\times$ acceptor product (Xia and Liu, 2001), yielding the $\mathrm{N}_{\mathrm{FRET}}$ parameter. Control experiments were performed on U87 pLG72-ECFP cells transiently transfected with pEYFP-C3 (0.5 $\mu \mathrm{g})$ vector and on U87 cells cotransfected with pEYFP-hDAAO-C3 $(2 \mu \mathrm{g})$ and pECFP-N1 $(0.5 \mu \mathrm{g})$ plasmids, $24 \mathrm{~h}$ upon transfection.

\section{Acknowledgments}

This work was supported by grants from MIUR prot. 2008N2FM4A 001 to L. Pollegioni, Fondo di Ateneo per la Ricerca to L. Pollegioni, S. Sacchi and S. Giovannardi, and Fondazione CARIPLO to L. Pollegioni. We wish to thank Luisa Guidali for expert support with confocal microscopy. P. Cappelletti is a student of the PhD program in Biotechnology, School in Biological and Medical Sciences, University of Insubria.

\section{Appendix A. Supplementary data}

Supplementary data to this article can be found online at doi:10. 1016/j.mcn.2011.06.001.

\section{References}

Arnold, G., Liscum, L., Holtzman, E., 1979. Ultrastructural localization of D-amino acid oxidase in microperoxisomes of the rat nervous system. J. Histochem. Cytochem. 27, 735-745.

Baumgart, F., Rodríguez-Crespo, I., 2008. D-amino acids in the brain: the biochemistry of brain serine racemase. FEBS J. 275, 3538-3545.

Bendikov, I., Nadir, S., Amar, S., Panizzutti, R., De Miranda, J., Wolosker, H., Agam, G. 2007. A CSF and postmortem brain study of D-serine metabolic parameters in schizophrenia. Schizophr. Res. 90, 41-51.

Benzel, I., Kew, J.N., Viknaraja, R., Kelly, F., de Belleroche, J., Hirsch, S., Sanderson, T.H. Maycox, P.R., 2008. Investigation of G72 (DAOA) expression in the human brain. BMC Psychiatry 8, 94. doi:10.1186/1471-244X-8-94.

Bossi, E., Soragna, A., Misner, A., Giovannardi, S., Frangione, V., Peres, A., 2007. Oligomeric structure of the neutral amino acid transporter KAAT1 and CAATCH1. Am. J. Cell. Physiol. 292, 379-387.

Caldinelli, L., Molla, G., Bracci, L., Lelli, B., Pileri, S., Cappelletti, P., Sacchi, S., Pollegioni, L., 2010. Effect of ligand binding on human D-amino acid oxidase: implications for the development of new drugs for schizophrenia treatment. Prot. Sci. 19, 1500-1512.

Chumakov, I., Blumenfeld, M., Guerassimenko, O., Cavarec, L., Palicio, M., Abderrahim, H., Bougueleret, L., Barry, C., Tanaka, H., La Rosa, P., Puech, A., Tahri, N., CohenAkenine, A., Delabrosse, S., Lissarrague, S., Picard, F.P., Maurice, K., Essioux, L. Millasseau, P., Grel, P., Debailleul, V., Simon, A.M., Caterina, D., Dufaure, I. Malekzadeh, K., Belova, M., Luan, J.J., Bouillot, M., Sambucy, J.L., Primas, G., Saumier, M., Boubkiri, N., Martin-Saumier, S., Nasroune, M., Peixoto, H., Delaye, A., Pinchot, V., Bastucci, M., Guillou, S., Chevillon, M., Sainz-Fuertes, R., Meguenni, S., AurichCosta, J., Cherif, D., Gimalac, A., Van Duijn, C., Gauvreau, D., Ouellette, G., Fortier, I., Raelson, J., Sherbatich, T., Riazanskaia, N., Rogaev, E., Raeymaekers, P., Aerssens, J., Konings, F., Luyten, W., Macciardi, F., Sham, P.C., Straub, R.E., Weinberger, D.R., Cohen, N., Cohen, D., 2002. Genetic and physiological data implicating the new human gene G72 and the gene for D-amino acid oxidase in schizophrenia. Proc. Natl. Acad. Sci. U. S. A. 99, 13675-13680

Graham, J., 2001. Biological Centrifugation. Taylor \& Francis, Inc Ed, p. 110

Hashimoto, K., Fukushima, T., Shimizu, E., Komatsu, N., Watanabe, H., Shinoda, N., Nakazato, M., Kumakiri, C., Okada, S., Hasegawa, H., Imai, K., Iyo, M., 2003. Decreased serum levels of D-serine in patients with schizophrenia: evidence in support of the N-methyl-D-aspartate receptor hypofunction hypothesis of schizophrenia. Arch. Gen. Psychiatry 60, 572-576.

Heresco-Levy, U., Javitt, D.C., Ebstein, R., Vass, A., Lichtenberg, P., Bar, G., Catinari, S. Ermilov, M., 2005. D-serine efficacy as add-on pharmacotherapy to risperidone and olanzapine for treatment-refractory schizophrenia. Biol. Psychiatry 57, 577-585.

Insel, T.R., 2010. Rethinking schizophrenia. Nature 468, 187-193.

Kvajo, M., Dhilla, A., Swor, D.E., Karayiorgou, M., Gogos, J.A., 2008. Evidence implicating the candidate schizophrenia/bipolar disorder susceptibility gene G72 in mitochondrial function. Mol. Psychiatry 13, 685-696.

Labrie, V., Roder, J.C., 2010. The involvement of the NMDA receptor D-serine/glycine site in the pathophysiology and treatment of schizophrenia. Neurosci. Biobehav. Rev. 3, 351-372.

Luo, B., Norris, C., Bolstad, E.S., Knecht, D.A., Grant, D.F., 2008. Protein quaternary structure and expression levels contribute to peroxisomal-targeting-sequence-1-mediated peroxisomal import of human soluble epoxide hydrolase. J. Mol. Biol. 380, 31-41.

Martineau, M., Baux, G., Mothet, J.P., 2006. D-serine signalling in the brain: friend and foe. Trends Neurosci. 29, 481-491.

Molla, G., Sacchi, S., Bernasconi, M., Pilone, M.S., Fukui, K., Pollegioni, L., 2006a. Characterization of human D-amino acid oxidase. FEBS Lett. 580, 2358-2364.

Molla, G., Bernasconi, M., Sacchi, S., Pilone, M.S., Pollegioni, L., 2006b. Expression in Escherichia coli and in vitro refolding of the human protein pLG72. Protein Expr. Purif. 46, 150-155.

Moreno, S., Nardacci, R., Cimini, A., Cerù, M.P., 1999. Immunocytochemical localization of D-amino acid oxidase in rat brain. J. Neurocytol. 28, 169-185.

Oliet, S.H., Mothet, J.P., 2009. Regulation of N-methyl-D-aspartate receptors by astrocytic D-serine. Neuroscience 158, 275-283.

Pollegioni, L., Sacchi, S., 2010. Metabolism of the neuromodulator D-serine. Cell. Mol. Life Sci. 67, 2387-2404

Pollegioni, L. Piubelli, L., Sacchi, S., Pilone, M.S., Molla, G., 2007. Physiological functions of D-amino acid oxidases: from yeast to humans. Cell. Mol. Life Sci. 64, 1373-1394.

Sacchi, S., Bernasconi, M., Martineau, M., Mothet, J.P., Ruzzene, M., Pilone, M.S., Pollegioni, L., Molla, G., 2008. pLG72 modulates intracellular D-serine levels through its interaction with D-amino acid oxidase: effect on schizophrenia susceptibility. J. Biol. Chem. 283, 22244-22256.

Schell, M.J., 2004. The N-methyl D-aspartate receptor glycine site and D-serine metabolism: an evolutionary perspective. Philos. Trans. R. Soc. Lond. B Biol. Sci. 359, 943-964.

Smith, K., 2010. Neuroscience: settling the great glia debate. Nature 468, 160-162.

Verrall, L., Burnet, P.W., Betts, J.F., Harrison, P.J., 2010. The neurobiology of D-amino acid oxidase and its involvement in schizophrenia. Mol. Psychiatry 15, 122-137.

Wolosker, H., Blackshaw, S., Snyder, S.H., 1999. Serine racemase: a glial enzyme synthesizing D-serine to regulate glutamate- $\mathrm{N}$-methyl-D-aspartate neurotransmission. Proc. Natl. Acad. Sci. U. S. A. 96, 13409-13414.

Xia, Z., Liu, Y., 2001. Reliable and global measurement of fluorescence resonance energy transfer using fluorescence microscopes. Biophysical J. 81, 2395-2402. 